\title{
A Sinodalidade Eclesial no Magistério do Papa Francisco
}

\author{
Eclesial Synodality in the magisterium of Pope Francis
}

\author{
Antonio Luiz Catelan Ferreira
}

\section{Resumo}

$\mathrm{O}$ artigo expõe e analisa as ideias eclesiológicas que fundamentam a compreensão da sinodalidade no Magistério do Papa Francisco, com especial atenção para o Discurso proferido na comemoração do $50^{\circ}$ aniversário da instituição dos Sínodo dos Bispos. Após uma reflexão que busca o significado do substantivo abstrato sinodalidade em sua correlação com o concreto sínodo, o estudo se desenvolve a partir de três abordagens sucessivas e complementares do objeto: seu enquadramento eclesiológico, que lhe fornece a base teológica; as atitudes sinodais ou elementos espirituais da sinodalidade; elementos formalmente sinodais que estruturam a praxe sinodal. O escopo é contribuir para uma melhor compreensão da sinodalidade e o desenvolvimento de sua prática.

Palavras-chave: Sinodalidade. Papa Francisco. Eclesiologia. Consultividade.

\section{Abstract}

The article exposes and analyses the foundational ecclesiological ideas in the comprehension of sinodality in the pope's Francis Magisterium, with special attention to the speech given during the celebration of 50th anniversary of Synod of Bishops. After a reflection on the mean of the abstract noun synodality in its relation to the concrete synod, the study develops from three successive and complementary approaches of the object: its Ecclesiological framework, which provides the theological basis; the synodal attitudes or 
spiritual elements of synodality; elements formally synodal that structure the praxis of sinodality. The objective is to contribute to a better understanding of sinodalidade and the development of your practice.

Keywords: Synodality. Pope Francis. Ecclesiology. Consultivity.

\section{Introdução}

Papa Francisco vem abordando o tema da sinodalidade desde o início de seu ministério como Bispo de Roma. Recorde-se particularmente a homilia na Solenidade de S. Pedro e S. Paulo, em 2013, quando afirmou: "devemos caminhar por esta estrada da sinodalidade". ${ }^{1}$ À Igreja Italiana, este ano, em discurso aos Bispos em Assembleia Geral (22/05/2017), pediu "respiro e passo sinodal". ${ }^{2}$ Aos participantes do V Convenio Nacional da Igreja Italiana, em 2015, ele havia pedido um caminho sinodal em toda a Itália, para aplicar a exortação apostólica Evangelii Gaudium. ${ }^{3}$ Formalmente, em documento Magisterial, a primeira ocorrência do termo se encontra no motu próprio Mitis Iudex Dominus Iesus, quando se refere ao ofício do Metropolita como "sinal distintivo da sinodalidade na Igreja". ${ }^{4}$

Também nos discursos de abertura e de conclusão das Assembleias do Sínodo dos Bispos em 2014 e 2015 ocorrem referências à sinodalidade. Porém, uma abordagem ampla e articulada teologicamente da temática se encontra no discurso para a comemoração dos 50 anos do Sínodo dos Bispos (19/10/2015). Nessa ocasião, o Papa desenvolveu mais detalhadamente o que pensa sobre este tema. ${ }^{5}$

Neste estudo, apresentam-se as ideias estruturantes desse discurso, reflete-

\footnotetext{
${ }^{1}$ FRANCISCO. "Homilia in Sollemnitate Sanctorum Petri et Pauli Apostolorum". Acta Apostolicae Sedis 105 (2013), p. 602.

${ }^{2}$ FRANCISCO. "Discurso por ocasião da 70a Assembleia Geral da Conferência Episcopal Italiana". Disponível em: <http://w2.vatican.va/content/francesco/pt/speeches/2017/may/documents/papa-francesco_20170522_70assemblea-cei.html>. Acesso em 01 de setembro de 2017. ${ }^{3}$ FRANCISCO. "Discorso ai partecipanti del V Convegno Nazionale della Chiesa Italiana". Acta Apostolicae Sedis 107 (2015), p. 1286.

${ }^{4}$ FRANCISCO. "Motu Proprio Mitis Iudex Dominus Iesus". Acta Apostolicae Sedis 107 (2015), p. 960.

${ }^{5}$ FRANCISCO. "Discorso in occasione della Commemorazione del 50.mo anniversario dell'Istituzione del Sinodo dei Vescovi”. Acta Apostolicae Sedis 107 (2015), pp. 1138-1150.
} 
se sobre sua importância e sobre alguns desafios em vista de sua aplicação e ensaia-se uma análise teológica de sua compreensão da sinodalidade eclesial.

\section{Sínodo e sinodalidade}

Sinodalidade é o substantivo abstrato e se compreende a partir do concreto sínodo e do adjetivo sinodal. "Sínodo", composto pela proposição sýn, junto, e pelo substantivo hodós, caminho, indica, literalmente, um caminho feito em conjunto pelo povo de Deus peregrino. A palavra "caminho", por sua vez, remete a Cristo, "caminho, verdade e vida" (Jo 14,6), e à condição dos cristãos - os de Cristo, os do caminho (At 9,2; 19,9.23; 22,4; 24,14.22).

Outra hipótese de etimologia vê a derivação de sínodo do antigo dialeto ático, e composta não a partir de hodós, mas de oudós, que significa a soleira da casa. ${ }^{6}$ Neste caso, sínodo significaria, então, estar reunidos num local ao qual se acedeu pela mesma entrada.

Comentando versículo inicial do Salmo 149, "ressoe seu louvor na Assembleia dos fiéis", S. João Crisóstomo afirma:

Em que consiste a ação de graças. - Vedes vós, como se deduz do louvor em coro, que antes da palavra requer a ação de graças, que se dá pela vida e pelas boas obras? Para a ação de graças não basta, pois, somente a palavra, sem que concorram as obras de virtude. Louvor a ele na assembleia dos santos. Aqui ensina ainda outra coisa. Mostra que é necessário oferecer o louvor ao mesmo tempo e com todos. A Igreja é uma assembleia, e sínodo é o seu nome. ${ }^{7}$

Em âmbito cristão, o antigo uso reserva a palavra "sínodo" para assembleias eclesiais, inclusive para a assembleia eucarística. ${ }^{8}$ É clássico considerar que o primeiro "Sínodo" ou "Concílio" tenha sido o que é relatado em At 15 e Gl 2,1-9. Sem entrar na discussão exegética sobre esses textos, ${ }^{9} \mathrm{o}$ certo é que aí se encontram diversos elementos que podem ser reconhecidos

${ }^{6}$ JOIN-LAMBERT, A. Les liturgies des synodes diocésains français 1983-1999. Paris: Éditions du Cerf, 2004, pp. 61-65.

7 JOÃO CRISÓSTOMO. Exp. in Psalm. 149,1.

${ }^{8}$ LAMPE, G. A Patristic Greek Lexicon. Oxford: Clarendon Press, 1968, pp. 1334-1335.

9 TAYLOR, J. "The 'Council' of Jerusalem in Acts 15". In: MELLONI, A.; SCATENA, S. (Ed.). Synod and Synodality: Theology, History, Cannon Law and Ecumenism in new contact. International Colloquium Bruges 2003. Münster: Lit, 2005, pp. 107-113. 
como propriamente sinodais, como: a reunião dos Apóstolos e presbíteros que se encontram à frente das Igrejas, e sua autoridade específica; a invocação do Espírito Santo como sinal da convicção de seu papel de guia da Igreja peregrina; a busca do discernimento pela verdade do Evangelho e pelo bem da Igreja; a escuta da comunidade, que se reúne, especialmente em oração; a ponderação atenta das várias posições sobre uma determinada matéria; a tomada de uma decisão que passa a ser considerada vinculante; a comunicação da decisão às diferentes Igrejas por escrito e com testemunhas. ${ }^{10}$

Segundo S. Pié-Ninot, ${ }^{11}$ o primeiro testemunho do uso técnico da palavra sínodo remonta a Eusébio de Cesareia. ${ }^{12}$ Ao que parece, a conexão do chamado "Concílio de Jerusalém" com os "sínodos episcopais" foi realizada pela primeira vez por S. João Crisóstomo. ${ }^{13}$

Do ponto de vista da história sinodal, considera-se que o primeiro sínodo tenha sido convocado em 155, na cidade de Roma, pelo Papa Anacleto, para tratar da questão da data da Páscoa. Há também opiniões de que o primeiro teria sido convocado pelo Papa Vítor, em 190. ${ }^{14}$

A realização de sínodos tornou-se uma praxe muitíssimo difundida, por todas as regiões. Neles se resolviam questões doutrinais e disciplinares num contexto de reconhecimento recíproco das várias Igrejas particulares. É tão característico da Catholica esse procedimento, que um estudioso das origens cristãs como o Card. J. Danielou chega a afirmar: "não há como não nos impressionar pela diferença entre a atuação dos fundadores de seita, que tem carácter pessoal semelhante aos chefes de escola, e a atuação dos bispos, que é essencialmente coletiva e tem por finalidade manifestar a fé comum" ${ }^{15}$ A este propósito, S. Ireneu afirmou que, enquanto os fundadores de seitas iniciavam cacofonias, os bispos testemunhavam "uma mesma fé e um mesmo modo de organização". ${ }^{16}$

Ao par da ampla atividade formalmente sinodal, encontram-se na

${ }^{10}$ WAGNER, H. "Sínodo/Concílio". In: EICHER, P. (Ed.). Dicionário de conceitos fundamentais de teologia. S. Paulo: Paulus, 1993, p. 830.

${ }^{11}$ PIÉ-NINOT, S. Eclesiología. La sacramentalidad de la comunidad Cristiana. Salamanca: Sigueme, 2007, p. 565.

${ }^{12}$ História Eclesiástica, VII, 27,2 Apud: PIÉ-NINOT, S. Eclesiología, p. 565.

${ }^{13}$ WAGNER, H. "Sínodo/Concílio", p. 830.

${ }^{14}$ CHIRON, Y. Histoire des conciles. Paris: Pérrin, 2011, p. 6.

${ }^{15}$ DANIÉLOU, J. "Des origines à la fin du troisième siècle". In: ROGIER, L.-J; AUBERT, R.; KNOWLES, M. D. Nouvelle histoire de l'église. Tomo 1. Paris: Éditions du Seuil, 1963, p. 141. ${ }^{16}$ Adv. Haer. V, 20,1 Apud: DANIÉLOU, J. "Des origines à la fin du troisième siècle", p. 141. 
Igreja antiga testemunhos como o de S. Cipriano, que na Carta 14, escrita na primavera de 250, exprime seu sofrimento por motivo de presbíteros e leigos que apostataram em meio à perseguição. Nessa carta encontram-se palavras que podem caracterizar um "espírito" sinodal, ou um "estilo" sinodal:

A respeito do que me escreveram Donato, Fortunato, Novato e Gordio, meus irmãos no sacerdócio, não posso responder sozinho, uma vez que decidi, desde o início do meu episcopado, não tomar nenhuma decisão por mim mesmo, sem o vosso conselho e sem o consenso do povo [nihil sine concilio vestro et sine consenso plebis]. Mas quando, com a graça de Deus, puder estar convosco, então trataremos em comum sobre o que foi feito e sobre o que se há de fazer, como o respeito que nos devemos exige. ${ }^{17}$

Aqui já se encontra num âmbito mais amplo que o da realização formal de sínodos. Trata-se de um estilo ou de um espírito que se pode bem designar com o substantivo abstrato "sinodalidade". A literatura eclesiológica que gravita em torno do Concílio Vaticano II nos habituou a termos como "colegialidade", por relação ao Colégio Episcopal, e "conciliaridade", por referência ao Concílio, embora "conciliaridade" não tenha tido o mesmo sucesso e não tenha se tornado tão comum no vocabulário teológico. Com a "sinodalidade", a reflexão eclesiológica se debruça sobre uma realidade mais ampla e complexa que os Sínodos - Sínodos diocesanos ou Sínodo dos Bispos. Porém, parece que não se pode compreendê-la somente como estilo ou espírito, em termos gerais. Em seu discurso na comemoração dos cinquenta anos do Sínodo dos Bispos, o Papa Francisco fala da sinodalidade como "dimensão constitutiva da Igreja". ${ }^{18} \mathrm{E}$ a articula com a colegialidade, destacando o papel específico dos bispos e do bispo de Roma.

Compreender e expressar adequadamente a dimensão sinodal da Igreja em vista da praxe sinodal é tarefa que se impõe aos teólogos nessa nova etapa da recepção do Concílio Vaticano II, cuja marca é a comemoração dos cinquenta anos de sua realização. Ela pode ser considerada uma chave de leitura privilegiada da eclesiologia conciliar e oferecer luzes para a compreensão de temas como a corresponsabilidade de todo o povo de Deus na vida a na missão da Igreja no mundo de hoje, a participação dos leigos e leigas nas tomadas de decisão e nas escolhas pastorais, a missão específica da responsabilidade dos pastores.

${ }^{17}$ CIPRIANO. Carta $V$, 4: PL 4, col. 234.

${ }^{18}$ FRANCISCO. "Discorso in occasione della Commemorazione", p. 1141. 
Consciente do horizonte aberto pela temática, estas reflexões se propõem reunir elementos do discurso pontifício na ocasião dos cinquenta anos do sínodo dos bispos e destacar seu potencial para o aprofundamento das questões tocadas por ele.

\section{Elementos para a compreensão da sinodalidade}

Distinguem-se aqui, no discurso de Francisco, três categorias de elementos: fundamentais, espirituais e formalmente sinodais. Os primeiros são de natureza eclesiológica, os seguintes se ligam a atitudes e os últimos são requeridos diretamente na operacionalização - se assim se pode dizer - da praxe sinodal.

São importantes também as indicações dadas por Francisco a respeito das implicações ecumênicas e culturais da sinodalidade. Elas não são tratadas aqui por motivo da escolha de elementos mais diretamente eclesiológicos.

\subsection{Elementos de base / fundamentais / Eclesiológicos}

Neste nível se encontra a eclesiologia do Concílio Vaticano II, especialmente a precisa articulação entre a totalidade do povo de Deus, o múnus específico dos pastores e corresponsabilidade dos leigos e leigas na missão eclesial, unitária por sua natureza.

2.1.1. A comum dignidade de todos os fiéis, o sensus fidei e a corresponsabilidade eclesial

Os fundamentos da sinodalidade, o Papa os indica a partir da eclesiologia do Concílio Vaticano II. Ele se refere explicitamente aos números 10 e 12 da Constituição dogmática Lumen gentium, do Concílio Vaticano II: todos os batizados como constituintes do povo de Deus; a unção espiritual dos fiéis e a infalibilidade in credendo; o consensus fidelium; a participação do povo de Deus na função profética de Cristo. Nesse contexto, o papa expressa o propriamente sinodal do sensus fidei: ele se caracteriza como um "olfato' para discernir as novas estradas que o Senhor abre para a Igreja". ${ }^{19}$ Trata-se do discernimento pastoral.

${ }^{19}$ FRANCISCO. "Discorso in occasione della Commemorazione", p. 1140. 
Como consequência, citando Evangeli Gaudium 119, nesse mesmo contexto, Francisco afirma que "cada batizado, seja qual for sua função na Igreja e o grau de instrução de sua fé, é um sujeito ativo de evangelização" e que "seria inadequado pensar em um esquema de evangelização levado à frente por atores qualificados no qual o resto do povo fiel fosse somente receptivo". Isto mostra que sua compreensão da sinodalidade está estreitamente ligada à missão, à evangelização.

\subsubsection{Os diversos níveis de exercício da sinodalidade}

A afirmação de Francisco de que o "primeiro nível de exercício da sinodalidade se realiza nas Igrejas particulares" ${ }^{20}$ porta consigo grande significado eclesiológico e importantes consequências práticas. É nesse nível que a escuta recíproca entre membros da Igreja pode ser mais ampla e mais direta. Nesse âmbito o papa pede valorização dos diversos instrumentos de colaboração e de participação, como o Conselho Presbiteral, Conselho Pastoral, Colégio dos Consultores, e outros.

O segundo nível leva a marca da colegialidade e inclui, como instrumento, os Concílios Particulares e as Conferências Episcopais. Destaca-se aqui a tomada de posição de Francisco diante da questão sobre a possibilidade de instâncias intermédias da colegialidade. ${ }^{21}$

O último nível é o da Igreja universal. Nela a sinodalidade se realiza em relação com a colegialidade episcopal na moldura da "solicitude pelo Povo de Deus". ${ }^{22}$ Novamente, nesse âmbito, Francisco, discretamente, toma posição sobre a forma de realização da colegialidade episcopal que se dá no Sínodo dos Bispos: fala de expressão da colegialidade e também, em outra parte, dos participantes do Sínodo dos Bispos como representantes do Colégio.

No tratamento que Francisco dá aos diversos níveis, transparece claramente a revalorização das Igrejas particulares promovida pelo Concílio Vaticano II. Nelas e a partir delas (in et ex quibus) existe a una e única Igreja de Cristo. ${ }^{23}$

\footnotetext{
${ }^{20}$ FRANCISCO. "Discorso in occasione della Commemorazione", p. 1142.

${ }^{21}$ FRANCISCO. "Discorso in occasione della Commemorazione", p. 1143.

${ }^{22}$ FRANCISCO. "Discorso in occasione della Commemorazione", p. 1143.

${ }^{23}$ CONCÍLIO ECUMÊNICO VATICANO II. "Constituição Dogmática Lumen gentium”, n. 23. In: CONCÍLIO ECUMÊNICO VATICANO II. Documentos. Brasília: Edições CNBB, 2018, p. 108.
} 


\subsubsection{Papel dos pastores em communio hierarchica}

Francisco utiliza a imagem da pirâmide para falar da missão própria dos pastores, recordando que o Colégio apostólico está no vértice da Igreja. Mas se trata, como explica, de uma pirâmide invertida, pois a natureza da autoridade eclesial, segundo o evangelho, é diaconal e, por isso, os que exercem autoridade na Igreja são chamados ministros. "É servindo o Povo de Deus que cada bispo se torna vicarius Christi para a grei a ele confiada". ${ }^{24}$ Trata-se da autoridade como serviço e do poder da cruz.

A Pedro, cabeça do Colégio apostólico, foi confiada a missão de “confirmar" os irmãos na fé. A compreensão do âmbito de atuação dos pastores é importante para os diversos aspectos da sinodalidade. Isto demarca melhor os limites do que cabe a quem preside as comunidades e os organismos de participação.

Na realização da colegialidade em instâncias intermédias, o papa reafirma a necessidade de "uma salutar "descentralização"”. ${ }^{25}$

Estas indicações parecem oferecer referências importantes para a discussão do significado do voto consultivo e para a elaboração de critérios em vista do esclarecimento da responsabilidade decisional.

\subsection{Elementos espirituais / atitudes sinodais}

\subsubsection{Compromisso com a vontade de Deus}

O elemento principal no nível espiritual é a busca da vontade de Deus para sua Igreja e para o mundo de hoje. Essa é a referência decisiva para o discernimento e, portanto, também para as tomadas de decisão.

\subsubsection{Discernimento espiritual e pastoral}

É preciso discernir novas estradas, escutar o que o Espírito Santo diz às Igrejas, discernir os problemas regionais. A conexão com a realidade é fundamental para o desenvolvimento da sinodalidade. Esta precisa estar "conexa com o "baixo"" e precisa "partir das pessoas". ${ }^{26}$ Os bispos devem

\footnotetext{
${ }^{24}$ FRANCISCO. "Discorso in occasione della Commemorazione", p. 1142.

${ }^{25}$ FRANCISCO. "Discorso in occasione della Commemorazione", p. 1143, citando LG 16 e 32.

${ }^{26}$ FRANCISCO. "Discorso in occasione della Commemorazione”, p. 1143, citando LG 16 e 32.
} 
saber distinguir entre a fé da Igreja e as "opiniões frequentemente mutáveis da opinião pública", ${ }^{27}$ ter presente, "diante dos olhos", "o bem da Igreja". ${ }^{28}$

Assim há dois polos que o discernimento precisa levar em conta: os sinais do Espírito presentes na realidade e a autenticidade da fé.

\subsubsection{Ambiente de oração}

A dimensão teologal-pneumatológica do discernimento sinodal requer a prática da oração. Desde o relato da assembleia de At 15, uma das formas, talvez aquela mais decisiva, de participação de toda a comunidade no caminho sinodal, seja a oração. "A oração confiante é a ação do coração quando se abre para Deus, quando se fazem calar todos os nossos humores para escutar a suave voz de Deus que fala no silêncio. Sem escutar a Deus todas as nossas palavras serão somente 'palavras' que não saciam e não ajudam. Sem deixarse guiar pelo Espírito todas as nossas decisões serão somente de 'decoração', que em vez de exaltar o Evangelho o encobrem e o escondem". ${ }^{29}$

\subsection{Elementos formais / praxe da sinodalidade}

Antes de tratar desses elementos, convém ter presente que eles devem manifestar o "dinamismo de comunhão que inspira todas as decisões eclesiais". A referência à comunhão e a questão das tomadas de decisão são aqui muito significativas. Podem ser consideradas verdadeiros critérios para o exercício concreto da sinodalidade.

\subsubsection{Consulta ampla a todo o povo de Deus}

O sensus fidei se traduz sinodalmente em consulta formal. ${ }^{30}$ Esta, contudo, não basta para auscultar o sensus fidei, afirma o papa, mas não pode ser transcurada, pois permite escutar "ao menos alguns". O início do processo sinodal se dá na escuta do povo. ${ }^{31}$

\footnotetext{
${ }^{27}$ FRANCISCO. "Discorso in occasione della Commemorazione", p. 1142.

${ }^{28}$ FRANCISCO. "Discurso aos Padres Sinodais na abertura dos trabalhos sinodais". Acta Apostolicae Sedis 107 (2015), pp. 1137.

${ }^{29}$ FRANCISCO. "Discurso aos Padres Sinodais na abertura dos trabalhos sinodais", p. 1137.

${ }^{30}$ FRANCISCO. "Discorso in occasione della Commemorazione", p. 1140.

${ }^{31}$ FRANCISCO. "Discorso in occasione della Commemorazione", p. 1141.
} 
A pergunta que se põe aqui é: como honrar mais amplamente o sensus fidei no processo sinodal? Trata-se, sem dúvida, das várias formas que a escuta recíproca pode assumir. Talvez a realização do diálogo direto em sede de Conselhos, Assembleias e congressos de estudo, nos vários níveis e instâncias da vida da Igreja e a participação mais ampla dos vários componentes do povo de Deus a partir de seu estado de vida e de sua competência específica com relação ao tema tratado. Diálogo e escuta são palavras fundamentais no léxico sinodal. "Uma Igreja sinodal é uma Igreja da escuta", afirma Francisco. Para ele, os processos sinodais são verdadeiro "dinamismo de escuta conduzido em todos os níveis da vida da Igreja". ${ }^{32}$

Tanto os sujeitos humanos - todos - precisam se escutar reciprocamente, quanto juntos precisam escutar o que o Espírito diz às Igrejas (Ap 2,7). Tratase de uma escuta teologal e eclesial. "Escutar é mais que ouvir", como já havia afirmado. ${ }^{33}$

A escuta e o diálogo precisam de adequadas traduções institucionais. $\mathrm{O}$ papa recorda que nos "organismos de comunhão" se encontram instrumentos que precisam ser cada vez mais ativados e valorizados para a colaboração entre fiéis e pastores pelo bem de toda a comunidade eclesial. ${ }^{34}$

\subsubsection{A missão sinodal dos pastores}

A segunda etapa do caminho sinodal é a escuta recíproca dos pastores. Aqui está presente uma teologia do episcopado e do primado entendida também a partir dos acentos que lhe conferiu o Concílio Vaticano II. Os bispos são considerados "custódios autênticos, intérpretes e testemunhas da fé de toda a Igreja". ${ }^{35}$

No âmbito da escuta dos pastores se situa a escuta do bispo de Roma como "Pastor e doutor de todos os cristãos", como afirma Francisco, citando a Constituição Dogmática Pastor Aeternus, do Concílio Vaticano I. ${ }^{36} \mathrm{O}$ Sucessor de Pedro não fala em nome de suas convicções pessoais, mas na

\footnotetext{
${ }^{32}$ FRANCISCO. "Discorso in occasione della Commemorazione", p. 1140.

33 FRANCISCO. "Exortação Apostólica Evangelii Gaudium”. Acta Apostolicae Sedis 105 (2013), p. 1092, n. 171.

${ }^{34}$ FRANCISCO. "Discorso in occasione della Commemorazione", p. 1140.

${ }^{35}$ FRANCISCO. "Discorso in occasione della Commemorazione", p. 1142.

${ }^{36}$ DENZINGER, H.; HÜNNERMAN, P. Compêndio dos símbolos, definições e declarações de fé e moral. São Paulo: Loyola - Paulinas, 2017, n. 3074.
} 
qualidade de "testemunha da fé de toda a Igreja". A missão sinodal dos pastores, especificamente do bispo de Roma, é garantir a unidade sem limitar a liberdade. ${ }^{37}$

Aqui a referência ao estilo sinodal é novamente importante. Não se pode resolver tudo com boas leis. $\mathrm{O}$ crescimento no caminho sinodal depende, em grande medida, de conversão sinodal, de atitudes e estilos, que respeitam as condições diferenciadas de todos os membros do povo de Deus como plenos sujeitos eclesiais.

\subsubsection{Voto}

Um dos principais problemas que se apresentam com relação aos organismos de participação, desde os Conselhos Pastorais Paroquiais até o Sínodo dos Bispos, é o do significado do voto e de seu valor teológico e jurídico. A ciência jurídica se concentra na interpretação da consultividade e das diferentes características que há entre a consultividade em âmbito civil e em âmbito eclesial. Situa o voto consultivo com relação à tomada de decisão que cabe ao pastor (Papa, Bispo, Pároco).

É preciso deter-se ainda um pouco na consultividade, ela que fundamenta a escuta mais ampla ao povo de Deus e não se restringe apenas à questão do voto. Nesse momento de retomada e de aprofundamento da sinodalidade, é oportuno perguntar-se, teologicamente, pelo significado conjunto da consultividade, do diálogo de discernimento eclesial e do voto. Qual o valor teológico da consulta? Qual o valor do voto dado em sede propriamente sinodal? A Igreja possui estrutura hierárquica e sinodal. No interior desse binômio é preciso procurar continuamente o equilíbrio, que nem sempre é fácil. Pode ser útil retomar a reflexão de J. Ratzinger, feita a partir de S. Cipriano:

Nihil sine espicopo (nada sem o Bispo); a exigência da participação pública e da unidade da Igreja local sob o Bispo atinge nele, na luta contra comunidades de eleitores e contra a formação de grupos, a sua forma mais nítida e mais clara. Mas o mesmo Cipriano declara, de modo não menos claro, perante o seu presbitério: nihil sine concilio vestro (nada sem o vosso conselho), e afirma dum modo igualmente claro à sua comunidade: nihil sine consenso plebes (nada sem o consenso do povo). Nesta tríplice forma de cooperação na construção da comunidade reside o modelo clássico

${ }^{37}$ FRANCISCO. "Discorso in occasione della Commemorazione", p. 1142. 
da "democracia" eclesial, que não nasce de uma transposição insensata de modelos estranhos à Igreja, mas da íntima estrutura do ordenamento eclesial e que, por isso, é conforme à exigência específica da sua essência. ${ }^{38}$

Além da referência à Carta $\mathrm{V}$, já citada, Ratzinger se refere à Carta LXIX, dirigida a Florêncio Pupiano, que tinha acusado S. Cipriano de vários crimes e que fomentava a divisão na comunidade. O metropolita afirma: "Deves saber que o Bispo se encontra na Igreja e a Igreja no Bispo; se alguém não está com o Bispo, não se encontra na Igreja". 39

Em 1859, o Beato J. H. Newman utilizou a noção de conspiratio em um artigo publicado na revista Rambler: "On Consulting the Faithful in Matters of Doctrine". ${ }^{40}$ Newman estava convencido, com base em seus estudos sobre a crise ariana do séc. IV, que, neste caso, a integridade do dogma tinha sido mantida não tanto graças à Santa Sé, aos Concílios ou aos Bispos, mas graças ao consensus fidelium. No artigo, Newman defendeu que o consenso dos fiéis poderia ser considerado como: $1^{\circ}$ ) um testemunho de fato do dogma apostólico; $2^{\circ}$ ) uma espécie de instinto profundamente presente no corpo místico de Cristo; $3^{\circ}$ ) um fruto da condução que o Espírito Santo exerce sobre a Igreja; e $4^{\circ}$ ) como resposta à oração. Acrescentando que, por meio da conspirativo, os dois, a Igreja docente e a Igreja discente são postas em conjunto como um duplo testemunho, uma ilustrando a outra e nunca dividindo. O consenso porta em si algo que falta quando os pastores ficam sós. Trata-se de um duplo testemunho da fé, que se ilumina reciprocamente, buscando um objetivo comum.

Newman afirma ainda que bispos e fiéis são porções eclesiais, com funções próprias. Mas nenhuma delas pode ser negligenciada. Segundo ele, na pastorum et fidelium conspiratio existe algo que não se encontra na consideração exclusiva dos Pastores.

\section{Conclusão}

O estilo fraterno, como característica fundamental das comunidades cristãs e a escuta recíproca de todos os membros da Igreja fazem com que a

\footnotetext{
${ }^{38}$ RATZINGER, J. “Democratizzazione della Chiesa?”, pp. 50-51.

${ }^{39}$ CIPRIANO, Carta LXIX, VIII: PL 4, col. 406.

${ }^{40}$ Publicado depois separadamente: NEWMAN, J. H. On Consulting the Faithful in Matters of Doctrine. New York: Sheed and Ward, 1961.
} 
sinodalidade constitutiva se torne efetiva em processos pastorais abertos, que incluem todos e sejam atentos às expectativas e às necessidades do mundo atual. Como o aconselhar na Igreja está em relação com a virtude da prudência, estando fundamentado no dom do conselho, situa-se no âmbito da atuação do Espírito Santo.

Juntamente com a sinodalidade informal resultante da escuta recíproca e da corresponsabilidade missionária, a prática mais formal da sinodalidade é necessária. Dificilmente esta poderia subsistir sem os meios institucionais e sem os processos que permitem que ela se desenvolva e se aperfeiçoe. Escutar é fundamental, mas é igualmente indispensável consultar formalmente e desenvolver processos decisionais nos quadros das instâncias sinodais.

A circularidade entre o sensus fidei e o sacerdócio comum dos fiéis (todos), o discernimento realizado pelos pastores (alguns) e a autoridade do protos (um) é uma característica fundamental da sinodalidade. Essa circularidade honra a comum dignidade e a corresponsabilidade batismal de todos. Ao mesmo tempo, a atuação dos pastores, em comunhão hierárquica. Garante que os processos sinodais se mantenham na obediência a Cristo.

A atuação da sinodalidade integra e atualiza "alguns aspectos do antigo ordenamento eclesiástico" ${ }^{41}$ com novas estruturas, surgidas a partir do Vaticano II, o que implica o aperfeiçoamento dos meios da sinodalidade. Estas escolhas e as necessárias mudanças são consequência do paradigma missionário. Segundo o Papa Francisco, isto "implica pôr em chave missionária as atividades habituais das Igrejas", cuja consequência é uma dinâmica de reforma das estruturas eclesiais que não é fruto de estudos sobre a organização eclesiástica, mas "é consequência da dinâmica da missão". ${ }^{42}$

Fazendo uma aplicação do que diz o Concílio sobre o discernimento eclesial dos sinais da presença ou do desígnio de Deus nos acontecimentos, nas expectativas e aspirações de nosso tempo, se pode esperar que do desenvolvimento da sinodalidade "aparecerá do modo mais claro que o povo de Deus e o gênero humano, no qual ele se insere, prestam-se um serviço mútuo, de forma que assim a missão da Igreja se manifesta como religiosa e, por isso mesmo, sumamente humana". ${ }^{43}$

\footnotetext{
${ }^{41}$ FRANCISCO. "Discorso in occasione della Commemorazione”, p. 1143.

${ }^{42}$ FRANCISCO. "Discorso nell'incontro con i vescovi responsabili del Consiglio Episcopale Latinoamericano (CELAM)”. Acta Apostolicae Sedis 105 (2013), pp. 698.

${ }^{43}$ CONCÍLIO ECUMÊNICO VATICANO II. "Constituição Pastoral Gaudium et spes", n. 11. In: CONCÍLIO ECUMÊNICO VATICANO II. Documentos. Brasília: Edições CNBB, 2018, p. 212.
} 


\section{Referências bibliográficas}

CHIRON, Y. Histoire des conciles. Paris: Pérrin, 2011.

CIPRIANO. Ep. ad presbyteros et diáconos: PL 4, col. 231-234.

CIPRIANO. Ep. ad Florentium Pupianum: PL 4, col. 400-407.

CONCÍLIO ECUMÊNICO VATICANO II. "Constituição Dogmática Lumen gentium”. In: CONCÍLIO ECUMÊNICO VATICANO II. Documentos. Brasília: Edições CNBB, 2018, pp. 75-173.

CONCÍLIO ECUMÊNICO VATICANO II. "Constituição Pastoral Gaudium et spes". In: CONCÍLIO ECUMÊNICO VATICANO II. Documentos. Brasília: Edições CNBB, 2018, pp. 199-329.

DANIÉLOU, J. "Des origines à la fin du troisième siècle". In: ROGIER, L.-J; AUBERT, R.; KNOWLES, M. D. Nouvelle histoire de l'église. Tomo 1. Paris: Éditions du Seuil, 1963, pp. 27-257.

DENZINGER, H.; HÜNNERMAN, P. Compêndio dos símbolos, definições e declarações de fé e moral. São Paulo: Loyola - Paulinas, 2017.

FRANCISCO. "Homilia in Sollemnitate Sanctorum Petri et Pauli Apostolorum". Acta Apostolicae Sedis 105 (2013), pp. 600-602.

FRANCISCO. "Discorso nell'incontro con i vescovi responsabili del Consiglio Episcopale Latinoamericano (CELAM)". Acta Apostolicae Sedis 105 (2013), pp. 697-705.

FRANCISCO. "Exortação Apostólica Evangelii Gaudium”. Acta Apostolicae Sedis 105 (2013), pp. 1019-1137.

FRANCISCO. "Discurso aos Padres Sinodais na abertura dos trabalhos sinodais". Acta Apostolicae Sedis 107 (2015), pp. 1136-1138.

FRANCISCO. "Discorso in occasione della Commemorazione del 50.mo anniversario dell'Istituzione del Sinodo dei Vescovi". Acta Apostolicae Sedis 107 (2015), pp. 1138-1150.

FRANCISCO. "Discorso ai partecipanti del V Convegno Nazionale della Chiesa Italiana”. Acta Apostolicae Sedis 107 (2015), pp. 1284-1293.

FRANCISCO. "Motu Proprio Mitis Iudex Dominus Iesus". Acta Apostolicae Sedis 107 (2015), pp. 958-967. 
FRANCISCO. "Discurso por ocasião da 70 Assembleia Geral da Conferência Episcopal Italiana". Disponível em: <http://w2.vatican.va/ content/francesco/pt/speeches/2017/may/documents/papa-francesco_20170522_70assemblea-cei.html $>$. Acesso em 01 de setembro de 2017.

JOÃO CRISÓSTOMO. Exp. in Psalm. 149, 1: PG 55, col. 493-494.

JOIN-LAMBERT, A. Les liturgies des synodes diocésains français 19831999. Paris: Éditions du Cerf, 2004.

LAMPE, G. A Patristic Greek Lexicon. Oxford: Clarendon Press, 1968.

NEWMAN, J. H. On Consulting the Faithful in Matters of Doctrine. New York: Sheed and Ward, 1961.

PIÉ-NINOT, S. Eclesiología. La sacramentalidad de la comunidad Cristiana. Salamanca: Sigueme, 2007.

RATZINGER, J. "Democratizzazione della Chiesa?”. In: RATZINGER, J.; MAIER, H. Democrazia nella Chiesa. Possibilità, limiti, pericoli. Roma: Paoline, 1971, pp. 5-53.

TAYLOR, J. "The 'Council' of Jerusalem in Acts 15". In: MELLONI, A.; SCATENA, S. (Eds.). Synod and Synodality: Theology, History, Cannon Law and Ecumenism in new contact. International Colloquium Bruges 2003. Münster: Lit, 2005, pp. 107-113.

WAGNER, H. "Sínodo/Concílio". In: EICHER, P. (Ed.). Dicionário de conceitos fundamentais de teologia. S. Paulo: Paulus, 1993, p. 830.

\section{Antonio Luiz Catelan Ferreira}

Doutor em Teologia pela Pontifícia Universidade Gregoriana (Roma) Professor na Pontifícia Universidade Católica do Rio de Janeiro Rio de Janeiro / RJ - Brasil E-mail: catelan@puc-rio.br

Recebido em: 26/02/18

Aprovado em: 18/04/18 